\title{
Upregulation of endoplasmic reticulum stress is associated with diaphragm contractile dysfunction in a rat model of sepsis
}

\author{
GUANGYU JIAO $^{1}$, LIYING HAO ${ }^{2}$, MENGMENG WANG ${ }^{1}$, BIN ZHONG ${ }^{1}$, MIAO YU ${ }^{1}$, \\ SHUANG ZHAO ${ }^{1}$, PINGPING WANG ${ }^{1}$, RUI FENG ${ }^{2}$, SHUTAO TAN $^{1}$ and LIU CHEN ${ }^{1}$ \\ ${ }^{1}$ Respiratory Department and Intensive Care Unit, Shengjing Hospital of China Medical University, Shenyang, \\ Liaoning 110004; ${ }^{2}$ Department of Pharmaceutical Toxicology, School of Pharmaceutical Sciences, \\ China Medical University, Shenyang, Liaoning 110001, P.R. China
}

Received November 1, 2015; Accepted November 2, 2016

DOI: $10.3892 / \mathrm{mmr} .2016 .6014$

\begin{abstract}
Sepsis often causes diaphragm contractile dysfunction. Endoplasmic reticulum (ER) stress has been implicated in muscle contractile dysfunction. However, it remains unknown if ER stress occurs in the diaphragm during sepsis. In the present study, rats were divided into 4 groups and received placebo or one of three durations of endotoxin treatment (24, $48 \mathrm{~h}$ and 7 days). Isometric contractile force of the diaphragm was measured and lung wet-to-dry ratio (W/D) was calculated. Hematoxylin and eosin (H\&E) staining of lung tissue was performed and electron microscopy assessed ER damage in the diaphragm during sepsis. The mRNA and protein expression of glucose-regulated protein $78 \mathrm{kDa}$ (GRP78), glucose-regulated protein $94 \mathrm{kDa}$ (GRP94), C/EBP homologous protein (CHOP), endoplasmic reticulum protein 44 (ERP44), protein disulfide-isomerase like protein (ERP57) and protein disulfide isomerase family A member 4 (ERP72) in diaphragm muscles were measured using reverse transcription-quantitative polymerase chain reaction and western blot analysis. The level of cleaved caspase- 12 was analyzed by western blot analysis. The results demonstrated that sepsis increased lung W/D. H\&E staining revealed that sepsis caused alveolar congestion, hemorrhage and rupture. Swollen and distended ER was observed using electron microscopy during sepsis and decreased diaphragm contractile function was also observed. The expression levels of ER stress markers (GRP78, GRP94, CHOP, ERP44, ERP57 and ERP72) and the level of cleaved caspase- 12 were significantly elevated in septic rats compared with control rats, particularly in the $48 \mathrm{~h}$ group. In conclusion, the present study indicated that weakened
\end{abstract}

Correspondence to: Dr Guangyu Jiao, Respiratory Department and Intensive Care Unit, Shengjing Hospital of China Medical University, 36 Sanhao Street, Shenyang, Liaoning 110004, P.R. China E-mail: jiaoguangyu_sj@163.com

Key words: sepsis, diaphragm muscle, endoplasmic reticulum stress, caspase diaphragm contraction and damaged ER in septic rats was associated with increased expression of ER stress markers.

\section{Introduction}

Sepsis, a major medical problem often leading to multiple organ failure, is one of the major causes of mortality in critical care medicine (1). Respiratory failure is a devastating consequence of septic shock, it contributes to reduced systemic oxygen delivery and leads to multiple organ failure and mortality. Contractile dysfunction of the diaphragm muscles has a central role in respiratory failure during sepsis (2-4). Previous studies indicate several mechanisms are responsible for sepsis-induced contractile dysfunction of diaphragm muscle, including the implication of oxygen-deprived free radicals, mitochondrial injury, excitation-contraction coupling damage and reduced expression of dihydropyridine receptor $\alpha 1$ subunit (DHPR $\alpha 1 \mathrm{~s})$ and ryanodine receptor 1 (RyR1) (5-7). However, little is known about the status of the endoplasmic reticulum (ER) within the diaphragm, a crucial regulator of muscle contraction, during sepsis.

ER is an extensive intracellular membranous network that is essential for the maintenance of cellular processes, including calcium signaling, protein assembly, calcium homeostasis and lipid biosynthesis $(8,9)$. Efficient functioning of the ER is crucial for cell function and survival. Perturbations of ER homeostasis by energy deprivation, infection, increased protein trafficking, expression of mutant proteins with folding defects and chemical triggers interfere with the proper functioning of the ER to create a condition called ER stress (10). To cope with ER stress conditions, the cell initiates several signaling cascades known as the unfolded protein response (UPR). UPR sensors are in an inactive state when coupled to glucose-regulated protein $78 \mathrm{kDa}$ (GRP78). During ER stress and accumulation of unfolded proteins, GRP78 is released, which allows upregulation of ER chaperones and activation of the ER-associated protein degradation pathway (8).

ER stress is considered an important contributing factor in a wide variety of pathologies, including diabetes, neurodegenerative disorders, obesity and ischemia-reperfusion heart diseases (11-13). It has been previously reported that ER stress may result in diminished cardiomyocyte contractile 
function, indicating a role for ER stress in compromised muscle function under pathological conditions including sepsis (14). To the best of our knowledge, the status of ER stress in the diaphragm during sepsis has not been previously reported.

The aim of the present study was to assess the effects of sepsis on the ER stress status of the diaphragm in a rat sepsis model. ER damage of the diaphragm during sepsis was evaluated by electron microscopy (EM). The present study also examined the expression of a series of ER stress markers using western blot analysis and reverse transcription-quantitative polymerase chain reaction (RT-qPCR).

\section{Materials and methods}

Animal preparation. The protocol of the present study was approved by the ethics committee of Shengjing Hospital of China Medical University (Shenyang, China) and conducted in accordance with the Animal Care Center Guidelines of the institution. Animals used in the present study were adult male Wistar rats (age, 3 weeks; weight, 250-350 g) obtained from the National Research Center (Giza, Egypt). The animals were housed in polyacrylic cages (five animals per cage) and provided access to food/water ad libitum. Rats were maintained at room temperature $\left(22-25^{\circ} \mathrm{C}\right)$ with a 12 -h light/dark cycle. Lipopolysaccharides (LPS), from Escherichia coli 055:B5 (cat no. L2880; lot no. 110M4086V; containing 3,000,000 endotoxin units per mg LPS) were obtained from Sigma-Aldrich (Merck Millipore, Darmstadt, Germany) and were administered intraperitoneally to rats ( 8 per group) in three experimental groups $(24,48 \mathrm{~h}$ and 7 days) at a dose of $8 \mathrm{mg} / \mathrm{kg}$. For the $24 \mathrm{~h}$ group, rats were euthanized $24 \mathrm{~h}$ after the first dose. For the $48 \mathrm{~h}$ and 7 day groups, an additional dose of $8 \mathrm{mg} / \mathrm{kg}$ was given $24 \mathrm{~h}$ after the first dose and rats were euthanized $48 \mathrm{~h}$ or 7 days after the original dose. An additional 8 rats were enrolled in the control group and were injected intraperitoneally with $1 \mathrm{ml}$ of normal saline as a placebo. All rats received normal saline subcutaneously to prevent dehydration. Animals were euthanized with an overdose of pentobarbital sodium (100 mg/kg), delivered intravenously. Diaphragm muscles were immediately excised from the midcostal region, with the insertion of fibers at the ribs and central tendon kept intact. The excised diaphragm muscles were prepared for investigation as previously described $(15,16)$.

Measurement of lung wet-to-dry ratio (W/D) and lung histopathology. For W/D, left lungs were weighed and subsequently dried for 3 days in an oven at $65^{\circ} \mathrm{C}$. The ratio of wet weight to dry weight was calculated to estimate lung edema (17). For hematoxylin and eosin (H\&E) staining, both lungs were cannulated and inflated with $4 \%$ paraformaldehyde. After overnight fixation at $4^{\circ} \mathrm{C}$, tissue was embedded in paraffin, sectioned, and stained. H\&E staining was performed and the scale of lung injury was determined by a pathologist who was blind to the experimental groups. Six sections (4- $\mu \mathrm{m}$ thick) from left and right lower lobes in each animal were examined to determine the scale of lung injury on the basis of alveolar congestion, hemorrhage, neutrophil infiltration into the airspace or vessel wall and thickness of alveolar wall/hyaline membrane formation. The scale of lung injury was measured on a $0-4$ scale as follows: 0 , no injury; 1 , injury in up to $25 \%$ of the field; 2 , injury in up to $50 \%$ of the field; 3 , injury in up to $75 \%$ of the field; and 4, diffuse injury (18-20).

Measurements of the contractile function of the diaphragm. The in vitro techniques used to measure isometric contractile force and fatigue index (FI) have been previously described (16,21). A strip of diaphragm was stimulated in vitro using monophasic rectangular pulses through a Grass S88 stimulator provided by AstroNova (West Warwick, RI, USA). Current intensity was adjusted until muscle produced maximal isometric tension $\left(\mathrm{P}_{0} ; 500 \mathrm{msec}\right.$ train and $\left.50 \mathrm{~Hz}\right)$ responses were obtained. The stimulus intensity was set at $125 \%$ of this current intensity value. The length at which the muscle produced maximal isometric tension $\left(\mathrm{L}_{0}\right)$ was determined. Then, $\mathrm{L}_{0}$ was measured using digital calipers. At $\mathrm{L}_{0}$, the peak twitch force $\left(\mathrm{P}_{\mathrm{t}}\right)$ was determined from a series of contractions induced by single-pulse stimuli. At $\mathrm{L}_{0}$, diaphragm force-frequency curves (measured at 10, 20, 40, 50, 75 and $100 \mathrm{~Hz}$ ) were determined using $1 \mathrm{sec}$ duration trains of stimuli with a minimum of 2-min intervals between each stimulus train. Forces were normalized for the muscle cross-sectional area (CSA), which was determined by the following formula: [Muscle mass $(\mathrm{g})] / \mathrm{L}_{0}(\mathrm{~cm}) \times$ muscle density $\left(\mathrm{g} / \mathrm{cm}^{3}\right)$. The fatigability of diaphragm muscles was evaluated through use of a test described in a previous report, which involved repetitive stimulation at $40 \mathrm{~Hz}$ in trains of $330 \mathrm{msec}$ duration, with one train repeated each sec (22). The FI was calculated as the ratio of magnitude of force generated after $2 \mathrm{~min}$ of stimulation to the magnitude of the initial force.

Assessment of endoplasmic reticulum damage. EM was performed, as previously described (21), on diaphragm muscle segments from the control and sepsis groups. After diaphragm muscle segments were fixed, dehydrated, polymerized and sliced, the muscle fibril orientation was determined using light microscopy. The blocks were then reoriented and ultra-thin sections (50-70 nm) were cut transversely, or parallel, to the muscle fiber axis. These sections were contrasted with uranyl acetate and bismuth subnitrate for transmission EM.

EM images were evaluated independently by two pathologists from Shengjing Hospital of China Medical University. A total of 100 ER per muscle sample $(n=8)$ were evaluated. Each ER was assessed for membrane integrity and normal morphological size. Membrane integrity was scored as 0 (normal) or 1 (damaged). The morphological size of the ER was scored as 0 (normal) or 1 (dilated). The scores of each ER were added to produce a final score. An ER with an intact membrane and normal morphological size was given a final score of 0 , while one with a damaged membrane and dilated ER was given a final score of 2 . The percentage of ER in each final score group $(0,1$ and 2$)$ within each sample was calculated.

Determination of ER stress markers using RT-qPCR. Rat diaphragms were homogenized with $1 \mathrm{ml}$ of RNAiso reagent (Takara Biotechnology Co., Ltd., Dalian, China), and total RNA was isolated according to the manufacturer's protocol. Recombinant DNase I (RNase-free; $2 \mu \mathrm{l}$; Takara Biotechnology Co., Ltd.) was added to each tube for $10 \mathrm{~min}$. The total RNA $(1 \mu \mathrm{g})$ was converted to cDNA by using PrimeScript RT 
Table I. Lung injury scores and W/D in control and sepsis groups.

\begin{tabular}{lcccc}
\hline & \multicolumn{3}{c}{ Groups } \\
\cline { 2 - 5 } Parameter & Control & $24 \mathrm{~h}$ & $48 \mathrm{~h}$ & 7 days \\
\hline Lung injury score & $0.08 \pm 0.05$ & $3.16 \pm 0.24^{\mathrm{a}}$ & $3.73 \pm 0.22^{\mathrm{a}, \mathrm{b}}$ & $2.26 \pm 0.26^{\mathrm{a}-\mathrm{c}}$ \\
W/D & $4.68 \pm 0.58$ & $6.49 \pm 0.74^{\mathrm{a}}$ & $6.68 \pm 0.61^{\mathrm{a}}$ & $5.92 \pm 0.62^{\mathrm{a}, \mathrm{c}}$ \\
\hline
\end{tabular}

${ }^{\mathrm{a}} \mathrm{P}<0.05$ vs. control; ${ }^{\mathrm{b}} \mathrm{P}<0.05$ vs. $24 \mathrm{~h}$ group; ${ }^{\mathrm{c}} \mathrm{P}<0.05$ vs. $48 \mathrm{~h}$ group. $\mathrm{n}=8$ per group. W/D, wet-to-dry ratio.

Master Mix kit (Takara Biotechnology Co., Ltd.) according to the manufacturer's protocol. qPCR was performed using SYBR Premix Ex Taq II (Takara Biotechnology Co., Ltd.) on the 7900HT Fast Real-Time PCR system (Applied Biosystems; Thermo Fisher Scientific, Inc. Waltham, MA, USA) as follows: $50^{\circ} \mathrm{C}$ for $2 \mathrm{~min}, 95^{\circ} \mathrm{C}$ for $10 \mathrm{~min}, 40$ cycles of $95^{\circ} \mathrm{C}$ for $15 \mathrm{sec}$, and $60^{\circ} \mathrm{C}$ for $60 \mathrm{sec}$. A dissociation procedure was performed to generate a melting curve for confirmation of amplification specificity. GAPDH served as the reference gene. The relative levels of gene expression were determined by $\Delta \mathrm{Cq}=(\mathrm{Cq}$ gene - $\mathrm{Cq}$ reference gene), and the fold change of gene expression was calculated by the $2^{-\Delta \Delta C q}$ method (23). Experiments were repeated in triplicate. The sequences of the primer pairs are as follows: GRP78 forward, 5'-AACATGGACCTGTTCC GCTCT-3' and reverse, 5'-CGAGTAGATCCGCCAAC CAG-3'; C/EBP homologous protein (CHOP) forward, 5'-CCC TCGCTCTCCAGATTCC-3' and reverse, 5'-GACCACTCT GTTTCCGTTTCCT-3'; glucose-regulated protein $94 \mathrm{kDa}$ (GRP94) forward, 5'-AAACGGCAACTCTTCGGTCA-3' and reverse, 5'-CCTCTGGCTCTTCCTCTACCTG-3'; endoplasmic reticulum protein 44 (ERP44) forward, 5'-AAGTCA CCAATCTTGATCGCAGT-3' and reverse, 5'-GCAGAAAGG AAGGCACAGTCAT-3'; protein disulfide-isomerase like protein (ERP57) forward, 5'-GAAGGTGGCCGTGAATTAA ATG-3' and reverse, 5'-CATTTGGCTGTTGCTTTAGA GGT-3'; protein disulfide isomerase family A member 4 (ERP72) forward, 5'-CAAATTTCACCACACTTTCAG CAC-3' and reverse, 5'-CATCCTGGGCTCATACTTG GAC-3'; and GAPDH forward, 5'-GCTGGTCATCAACGGG AAA-3' and reverse, 5'-CGCCAGTAGACTCCACGACAT-3'.

Western blot analysis. Total protein from rat diaphragm tissue was extracted using cell lysis buffer (Pierce; Thermo Fisher Scientific, Inc.) and quantified using the Bradford assay. Protein $(50 \mu \mathrm{g})$ was loaded per lane and separated on a $12 \%$ SDS-PAGE gel. After transferring to a polyvinylidene fluoride membrane (EMD Millipore, Billerica, MA, USA), the membrane was blocked with $5 \%$ bovine serum albumin (BSA) buffer $(5 \mathrm{~g}$ BSA/100 ml Tris-buffered saline with Tween-20) and then incubated overnight at $4^{\circ} \mathrm{C}$ with antibodies against GRP78 (rabbit monoclonal; 1:1,000; cat. no. 3177), CHOP (rabbit monoclonal; 1:1,000; cat. no. 5554), GRP94 (rabbit polyclonal; 1:1,000; cat. no. 2104), ERP44 (rabbit polyclonal; 1:1,000; cat. no. 2886), ERP57 (rabbit polyclonal; 1:1,000; cat. no. 2887), ERP72 (rabbit polyclonal; 1:1,000; cat. no. 2798), caspase-12 (rabbit polyclonal; 1:1,000; cat. no. 2202) (all from Cell Signaling Technology, Inc., Danvers, MA, USA) and GAPDH (rabbit polyclonal; 1:2,000; Santa Cruz Biotechnology, Inc.,
Dallas, TX, USA; cat. no. sc-25778). Following incubation with peroxidase-conjugated anti-mouse/rabbit IgG (1:1,000; Cell Signaling Technology, Inc.; cat. no. 5127) at $37^{\circ} \mathrm{C}$ for $2 \mathrm{~h}$, bound proteins were visualized using Pierce ECL Western Blotting Substrate (Thermo Fisher Scientific, Inc.) and detected using DNR imaging systems (DNR Bio-Imaging Systems, Ltd., Jerusalem, Israel). The relative protein levels were calculated by normalizing to GAPDH protein as a loading reference from three blots using ImageJ software (imagej.nih.gov/).

Statistical analysis. Data are presented as the mean \pm standard deviation. One-way analysis of variance, followed by Tukey's post hoc test, was applied to identify any significant differences between the control and sepsis groups using the SPSS software (version 17.0; SPSS Inc., Chicago, IL, USA). $\mathrm{P}<0.05$ was considered to indicate a statistically significant difference.

\section{Results}

Sepsis causes lung injury and increases lung W/D. As presented in Table I, the lung W/D, which indicates the level of lung edema, was significantly increased in the 3 sepsis groups compared with the control $(\mathrm{P}<0.05)$. The ratio reached its highest level at $48 \mathrm{~h}$ and decreased at day $7(\mathrm{P}=0.013)$.

As demonstrated in Fig. 1, microscopic analysis of the control group revealed marked alveoli, a thin alveolar septum and absence of congestion or edema. At 24 and $48 \mathrm{~h}$ following the first LPS dose, significant pulmonary alveolar congestion, hemorrhage and pulmonary interstitial edema associated with inflammatory infiltration were visible. The level of alveolar congestion and hemorrhage was reduced at day 7 compared with at 24 and $48 \mathrm{~h}$. The boundaries of the alveolar septum became thick and inflammatory infiltration was reduced compared with 24 and $48 \mathrm{~h}$ following the initial LPS dose. Lung injury scores are summarized in Table I. The level of lung injury was most severe at $48 \mathrm{~h}$ and reduced at day 7 compared with at 24 and $48 \mathrm{~h}(\mathrm{P}<0.05)$.

Sepsis reduces contractile force and FI of diaphragms. $\mathrm{P}_{\mathrm{t}} / \mathrm{CSA}$ and FI were significantly lower in the sepsis groups compared with the control group $(\mathrm{P}<0.05)$, with the exception of $\mathrm{P}_{\mathrm{t}} / \mathrm{CSA}$ in the 7 day group. $\mathrm{P}_{\mathrm{t}} / \mathrm{CSA}$ and FI were lowest at $48 \mathrm{~h}$ following the original dose of LPS ( $\mathrm{P}<0.05$ vs. control; Table II). At day 7, $\mathrm{P}_{\mathrm{t}}(\mathrm{P}=0.007)$ and $\mathrm{FI}(\mathrm{P}=0.016)$ increased significantly compared with the $48 \mathrm{~h}$ group. Compared with the control group, $\mathrm{P}_{0} / \mathrm{CSA}$ in the sepsis groups declined across the entire stimulation frequency range $(10-100 \mathrm{~Hz})$, which was 

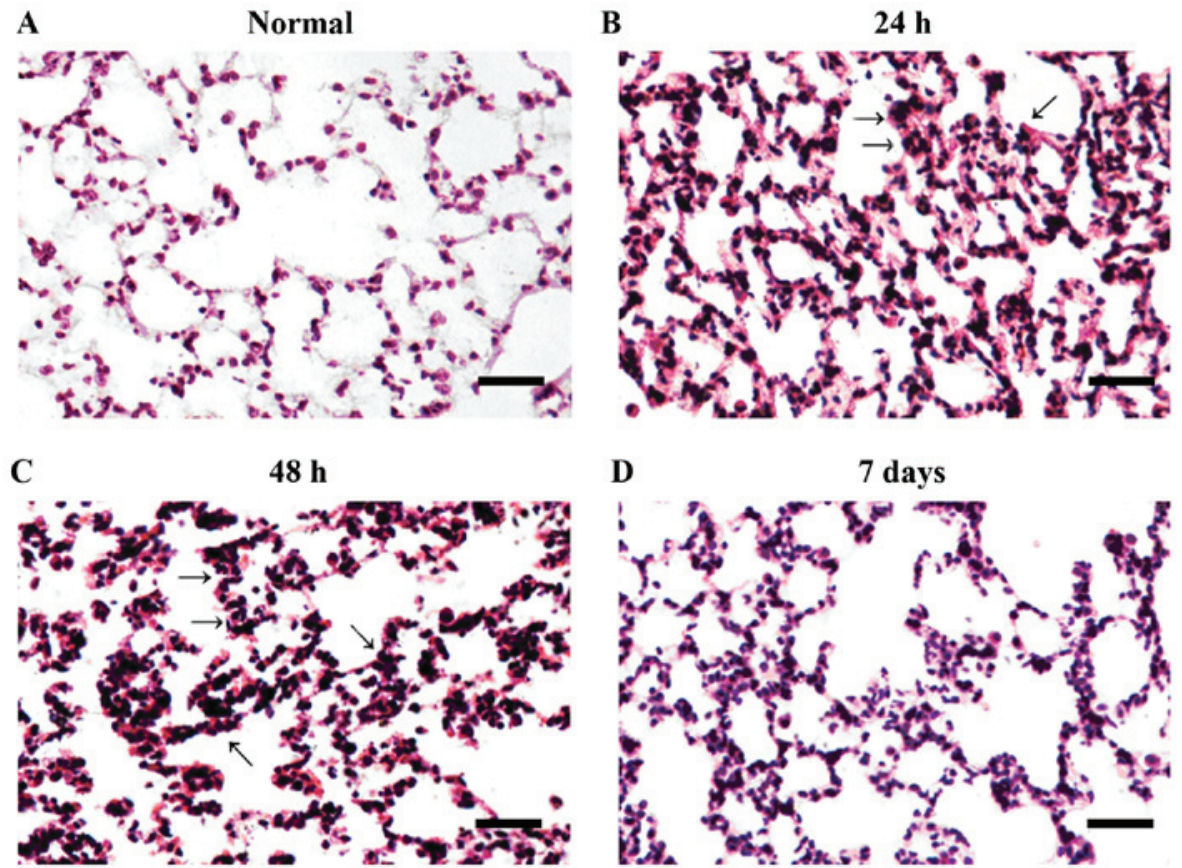

Figure 1. H\&E staining of lung tissue. (A) H\&E stained sections of lung tissue from control rats and rats from the (B) $24 \mathrm{~h}$ group, (C) $48 \mathrm{~h}$ group and (D) $7 \mathrm{days}$ group. The control group exhibited marked alveoli, thin alveolar septum and no congestion or edema. In the $24 \mathrm{~h}$ group there was congestion, hemorrhage and infiltration of inflammatory cells, predominantly neutrophils, as indicated by arrows. Lung injury was more severe in the $48 \mathrm{~h}$ group compared with the $24 \mathrm{~h}$ group. The level of alveolar congestion and hemorrhage was reduced in the 7 day group, the boundaries of the alveolar septum became thick and inflammatory infiltration was reduced (bar, $20 \mu \mathrm{m}$ ). $\mathrm{H} \& \mathrm{E}$, hematoxylin and eosin.

Table II. FI and $\mathrm{P}_{\mathrm{t}} / \mathrm{CSA}$ in control and sepsis groups.

\begin{tabular}{lcrrr}
\hline & \multicolumn{3}{c}{ Groups } \\
\cline { 2 - 4 } Parameter & Control & $24 \mathrm{~h}$ & $48 \mathrm{~h}$ & 7 days \\
\hline FI $(\%)$ & $31.88 \pm 3.59$ & $23.12 \pm 3.14^{\mathrm{a}}$ & $21.63 \pm 2.37^{\mathrm{a}}$ & $25.63 \pm 3.38^{\mathrm{a}, \mathrm{c}}$ \\
$\mathrm{P}_{\mathrm{t}} / \mathrm{CSA}\left(\mathrm{N} / \mathrm{cm}^{2}\right)$ & $2.53 \pm 0.30$ & $1.98 \pm 0.25^{\mathrm{a}}$ & $1.87 \pm 0.29^{\mathrm{a}}$ & $2.47 \pm 0.35^{\mathrm{b}, \mathrm{c}}$ \\
\hline${ }^{\mathrm{a} P}<0.05$ vs. control; ${ }^{\mathrm{b}} \mathrm{P}<0.05$ vs. 24 h group; ${ }^{\mathrm{C}} \mathrm{P}<0.05$ vs. 48 h group. $\mathrm{n}=8$ per group. FI, fatigue index; $\mathrm{P}_{\mathrm{t}}$, peak twitch force; CSA, cross-sectional \\
area.
\end{tabular}

Table III. Force/CSA at different stimulation frequencies in control and sepsis groups.

\begin{tabular}{lrrrr}
\hline & \multicolumn{3}{c}{ Groups } \\
\cline { 2 - 5 } $\left.\mathrm{P}_{0} / \mathrm{CSA}\right)\left(\mathrm{N} / \mathrm{cm}^{2}\right)$ & \multicolumn{1}{c}{ Control } & $24 \mathrm{~h}$ & $48 \mathrm{~h}$ & 7 days \\
\hline $10 \mathrm{~Hz}$ & $2.78 \pm 0.35$ & $2.15 \pm 0.29^{\mathrm{a}}$ & $2.03 \pm 0.22^{\mathrm{a}}$ & $2.6 \pm 0.39^{\mathrm{b}, \mathrm{c}}$ \\
$20 \mathrm{~Hz}$ & $6.53 \pm 0.69$ & $4.51 \pm 0.56^{\mathrm{a}}$ & $4.22 \pm 0.65^{\mathrm{a}}$ & $5.02 \pm 0.51^{\mathrm{a}, \mathrm{c}}$ \\
$40 \mathrm{~Hz}$ & $11.29 \pm 0.89$ & $7.85 \pm 0.82^{\mathrm{a}}$ & $7.34 \pm 0.65^{\mathrm{a}}$ & $8.64 \pm 0.74^{\mathrm{a}, \mathrm{c}}$ \\
$50 \mathrm{~Hz}$ & $14.32 \pm 1.57$ & $10.45 \pm 1.06^{\mathrm{a}}$ & $8.75 \pm 1.05^{\mathrm{a}, \mathrm{b}}$ & $12.83 \pm 1.10^{\mathrm{a}-\mathrm{c}}$ \\
$75 \mathrm{~Hz}$ & $16.29 \pm 1.43$ & $11.06 \pm 1.04^{\mathrm{a}}$ & $10.98 \pm 1.56^{\mathrm{a}}$ & $14.23 \pm 2.01^{\mathrm{a}-\mathrm{c}}$ \\
$100 \mathrm{~Hz}$ & $13.19 \pm 1.49$ & $10.32 \pm 0.96^{\mathrm{a}}$ & $8.96 \pm 0.91^{\mathrm{a}, \mathrm{b}}$ & $11.49 \pm 1.09^{\mathrm{a}-\mathrm{c}}$
\end{tabular}

${ }^{\mathrm{a}} \mathrm{P}<0.05$ vs. control; ${ }^{\mathrm{b}} \mathrm{P}<0.05$ vs. $24 \mathrm{~h}$ group; ${ }^{\mathrm{c}} \mathrm{P}<0.05$ vs. $48 \mathrm{~h}$ group. $\mathrm{n}=8$ per group. CSA, cross-sectional area; $\mathrm{P}_{0}$, maximal isometric tension.

most significant at $48 \mathrm{~h}$ following the initial LPS dose $(\mathrm{P}<0.05$; Table III). At day 7, $\mathrm{P}_{0} / C S A$ was increased compared with at $48 \mathrm{~h}$ across the entire stimulation frequency range $(\mathrm{P}<0.05)$.
Sepsis causes ultrastructural alteration of the ER. Ultrastructural changes of the ER were investigated using EM. As demonstrated in Fig. 2, the diaphragm in sepsis groups 

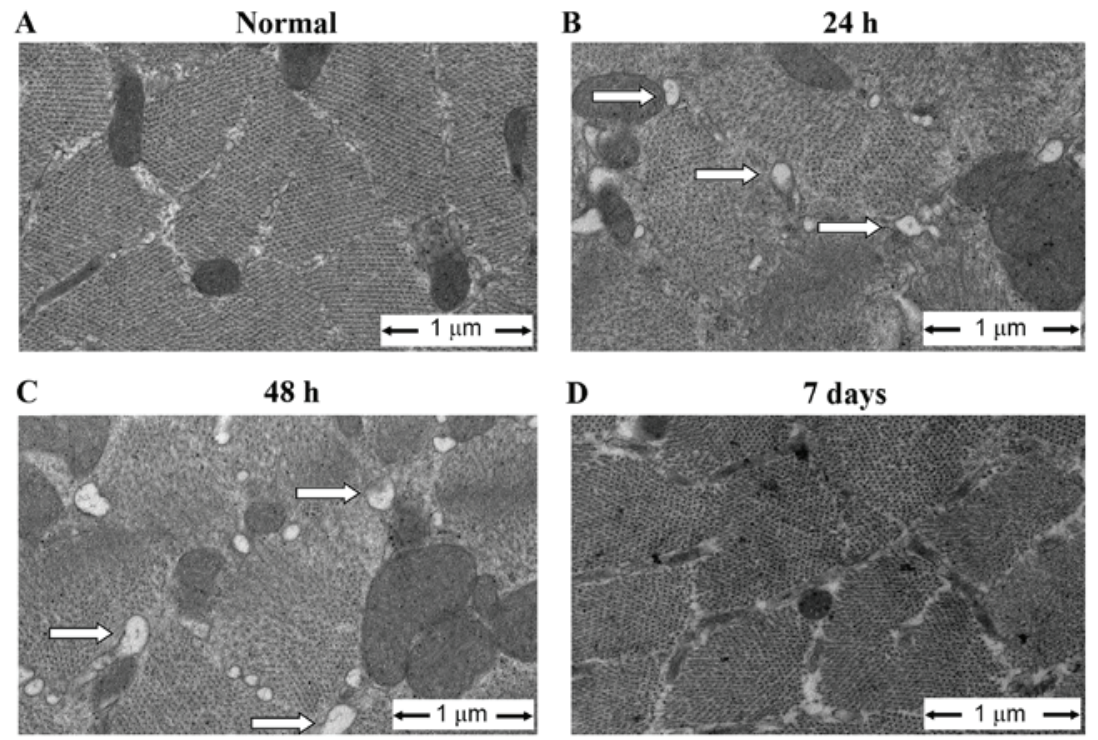

Figure 2. Ultrastructure of ER in diaphragm muscles. (A) Control group demonstrates the ultrastructure of normal ER. (B) LPS-treated $24 \mathrm{~h}$ group. (C) LPS-treated $48 \mathrm{~h}$ group. White arrow, distended ER with irregular shape. (D) ER damage was alleviated at 7 days (bar, $1 \mu \mathrm{m}$ ). ER, endoplasmic reticulum; LPS, lipopolysaccharide.

Table IV. ER injury scores in control and sepsis groups.

\begin{tabular}{lrrrr}
\hline & \multicolumn{4}{c}{ Groups } \\
\cline { 2 - 5 } Score & \multicolumn{1}{c}{ Control } & \multicolumn{1}{c}{$24 \mathrm{~h}$} & $48 \mathrm{~h}$ & 7 days \\
\hline 0 & $93.38 \pm 0.92$ & $73.00 \pm 4.14^{\mathrm{a}}$ & $71.13 \pm 3.13^{\mathrm{a}}$ & $82.63 \pm 2.72^{\mathrm{a}-\mathrm{c}}$ \\
1 & $5.87 \pm 1.13$ & $21.75 \pm 4.06^{\mathrm{a}}$ & $22.50 \pm 2.73^{\mathrm{a}}$ & $13.63 \pm 1.41^{\mathrm{a}-\mathrm{c}}$ \\
2 & $0.75 \pm 0.71$ & $5.25 \pm 1.04^{\mathrm{a}}$ & $6.38 \pm 1.30^{\mathrm{a}, \mathrm{b}}$ & $2.00 \pm 0.93^{\mathrm{a}-\mathrm{c}}$
\end{tabular}

Values are $\%$ of ER with each score per muscle sample. ${ }^{a} \mathrm{P}<0.05$ vs. control; ${ }^{\mathrm{b}} \mathrm{P}<0.05$ vs. $24 \mathrm{~h}$ group; ${ }^{\mathrm{c}} \mathrm{P}<0.05 \mathrm{vs}$. $48 \mathrm{~h}$ group. $\mathrm{n}=8$ per group. ER, endoplasmic reticulum.

exhibited swollen and distended ER with an irregular shape. Other ultrastructural abnormalities included swollen, degenerated mitochondria with a loss of cristae. ER damage was most obvious in the $48 \mathrm{~h}$ group and alleviated at 7 days. Additional ER ultrastructural changes were quantified by assessing membrane integrity and morphological size. As demonstrated in Table IV, the percentage of intact ER in each muscle sample (score 0) was decreased, and the percentage of damaged ER in each muscle sample (scores 1 and 2) was increased, in sepsis groups compared with the control $(\mathrm{P}<0.05)$.

Sepsis regulates protein and $m R N A$ expression of ER stress markers in diaphragm. The role of ER stress in the pathophysiology of sepsis and its complications has been demonstrated recently $(24,25)$. However, whether ER stress is involved in contractile dysfunction of the diaphragm in septic rats has not been investigated. GRP78, CHOP and GRP94 are key markers of ER stress. ERP44, ERP57 and ERP72 are ER chaperones that can be upregulated by the UPR at transcriptional level. In the present study, western blot analysis and RT-qPCR were performed to detect the expression of these proteins in the diaphragm. As demonstrated in Fig. 3, in the $24 \mathrm{~h}$ group, the expression levels of CHOP and ERP57 were significantly higher than in the control group $(\mathrm{P}<0.05)$. In the $48 \mathrm{~h}$ group, levels of GRP78, CHOP, GRP94, ERP44, ERP57 and ERP72 were significantly higher than in the control and $24 \mathrm{~h}$ groups $(\mathrm{P}<0.05)$. Expression of these proteins returned to normal levels at day 7. In addition, a caspase-12 antibody, which indicated cleaved caspase-12 at $35 \mathrm{kDa}$, was used to indicate the level of ER stress. The level of cleaved caspase-12 increased in sepsis groups and reached its highest level in the $48 \mathrm{~h}$ group, where the increase was statistically significant compared with the control $(\mathrm{P}=0.001)$.

Changes in the mRNA levels of these ER stress markers were also examined by RT-qPCR. As demonstrated in Fig. 4, significant increases in GRP78, CHOP, GRP94, ERP44, ERP57 and ERP72 mRNA were observed at 24 and $48 \mathrm{~h}$ compared with the control $(\mathrm{P}<0.05)$. Upregulated mRNA expression of ER stress markers declined at day 7, to a level that was similar to the control group.

\section{Discussion}

The present study demonstrated that weakened diaphragm muscle contractile force is associated with lung injury, ER damage and increased protein and mRNA expression of ER 

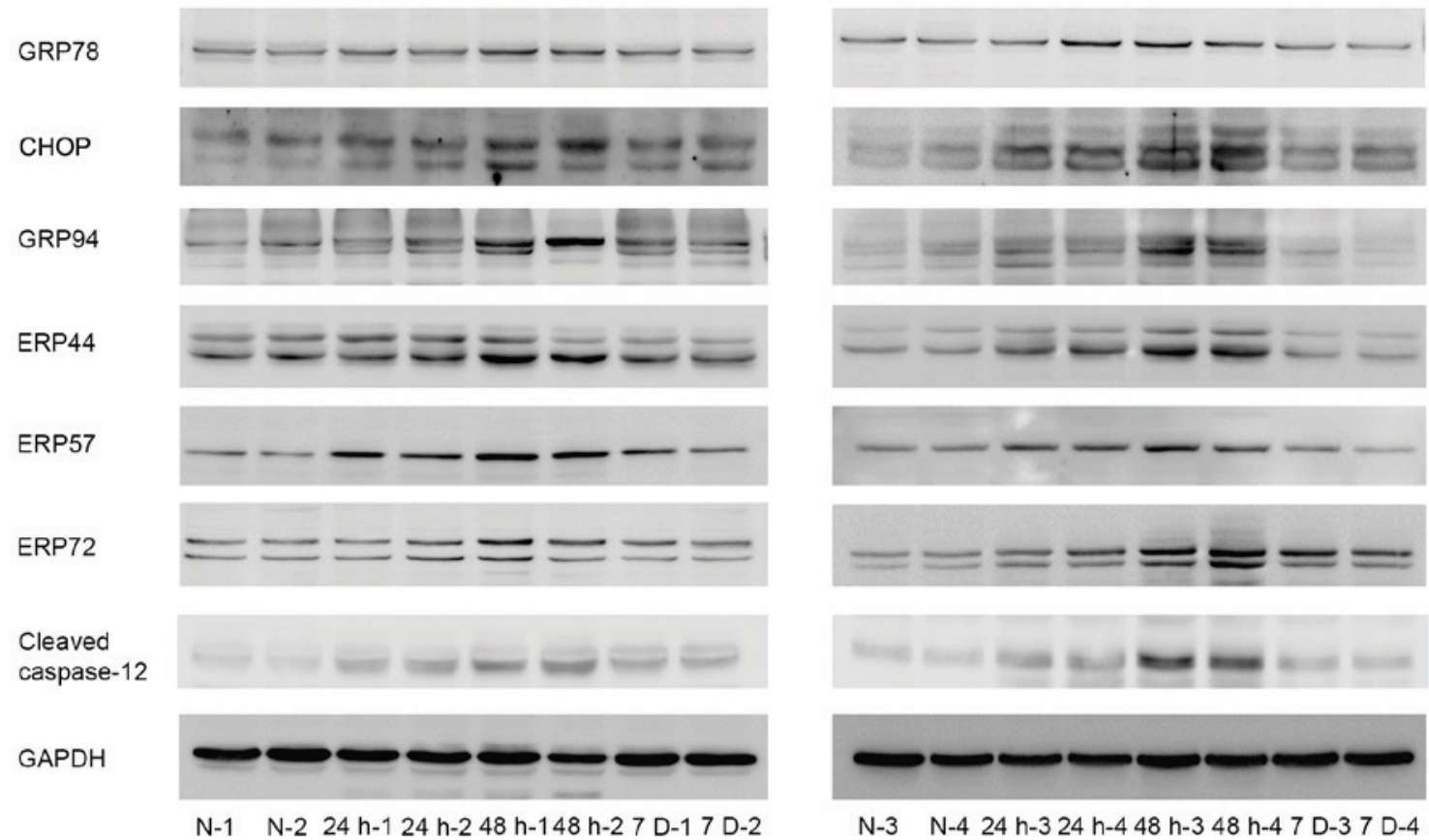

N-3 N-4 24 h-3 24 h-4 48 h-3 48 h-4 7 D-3 7 D-4
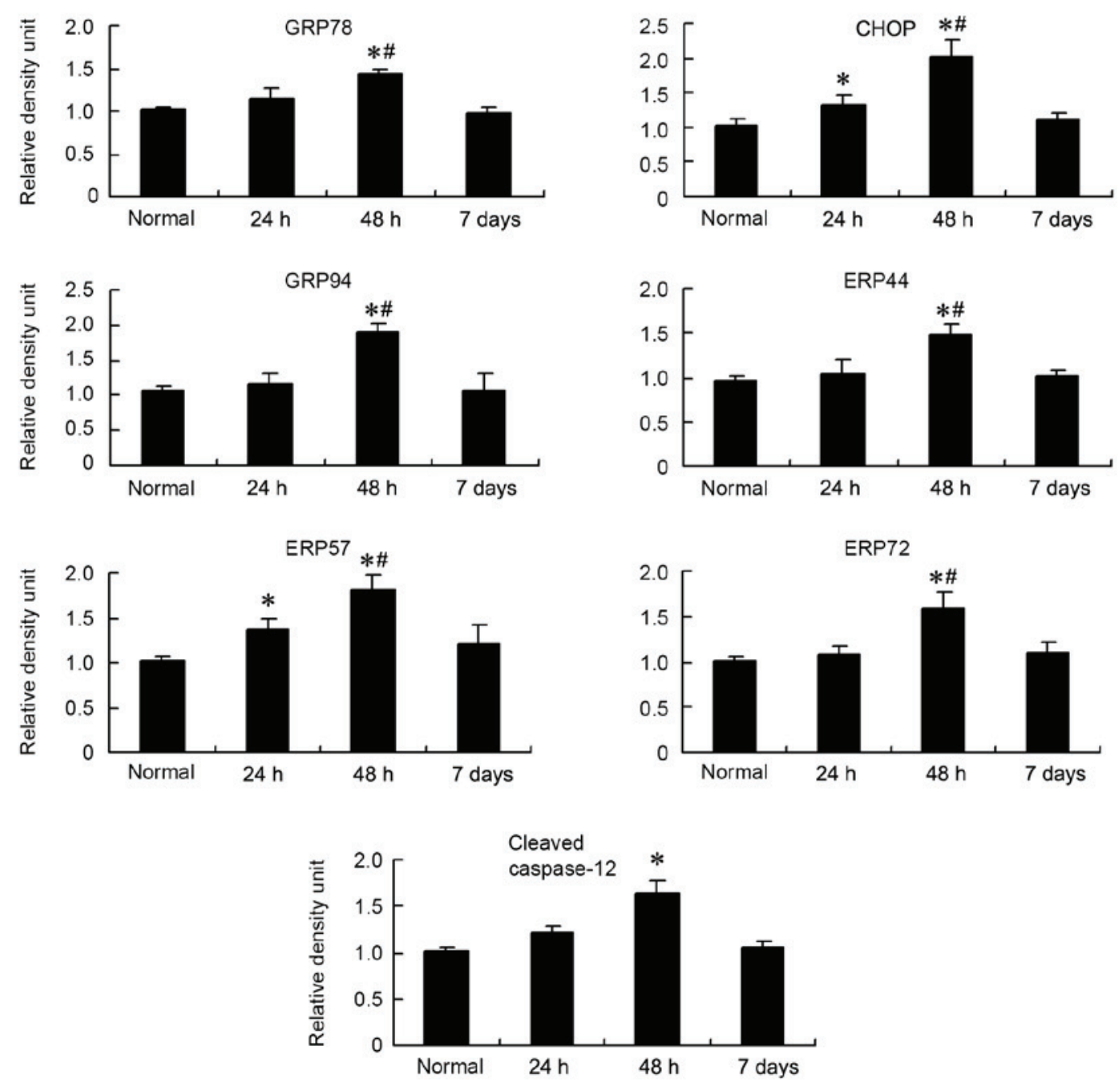

Figure 3. Western blot analysis of protein expression levels of ER stress markers in the diaphragm of the sepsis and control groups. Western blot and grey value analysis results indicated that expression of CHOP and ERP57 in the $24 \mathrm{~h}$ group was significantly higher than that in control group. In the $48 \mathrm{~h}$ group, levels of GRP78, CHOP, GRP94, ERP44, ERP57 and ERP72 were significantly higher than that in control and $24 \mathrm{~h}$ groups. Expression of cleaved caspase-12 in $48 \mathrm{~h}$ group was significantly higher than that in control group. Samples from 4 subjects in each group are presented. Values in the bar graph are presented as the mean \pm standard deviation. " $\mathrm{P}<0.05$ vs. the control, ${ }^{~} \mathrm{P}<0.05$ vs. the $24 \mathrm{~h}$ group. ER, endoplasmic reticulum; GRP78, glucose-regulated protein $78 \mathrm{kDa}$; $\mathrm{CHOP}$, C/EBP homologous protein; GRP94, glucose-regulated protein $94 \mathrm{kDa}$; ERP44, endoplasmic reticulum protein 44; ERP57, protein disulfide-isomerase like protein; ERP72, protein disulfide isomerase family A member 4. 

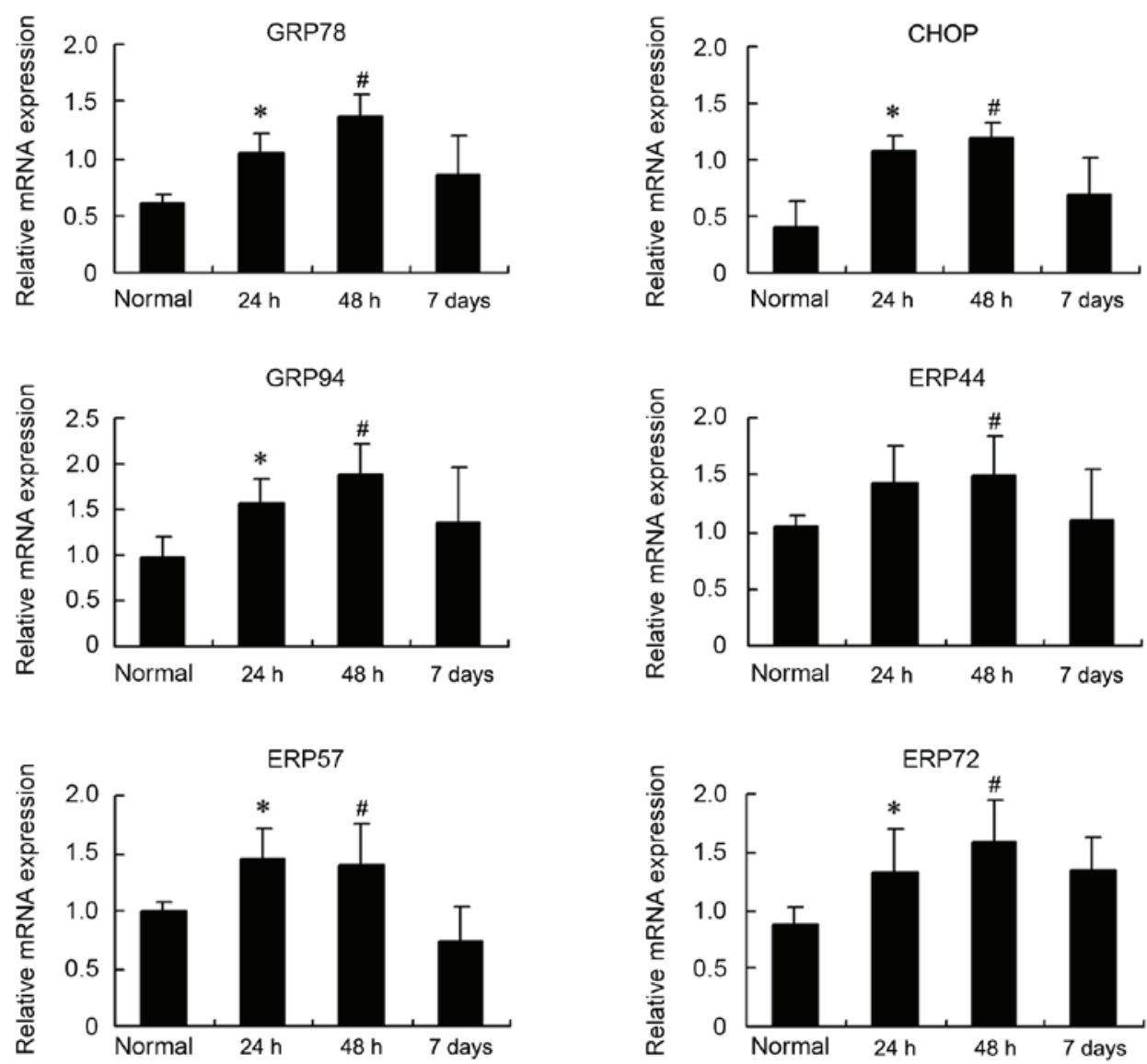

Figure 4. Reverse transcription-quantitative polymerase chain reaction analysis of mRNA expression levels of ER stress markers in the diaphragm from sepsis and control groups. Changes in the relative expression of mRNA, in control and the three different sepsis groups, for the following ER stress markers are presented as the mean \pm standard deviation: GRP78, CHOP, GRP94. ERP44, ERP57 and ERP72. "P $<0.05$ vs. the control, ${ }^{*} \mathrm{P}<0.05$ vs. the control. ER, endoplasmic reticulum; GRP78, glucose-regulated protein $78 \mathrm{kDa}$; CHOP, C/EBP homologous protein; GRP94, glucose-regulated protein $94 \mathrm{kDa}$; ERP44, endoplasmic reticulum protein 44; ERP57, protein disulfide-isomerase like protein; ERP72, protein disulfide isomerase family A member 4.

stress-associated factors, GRP78, CHOP, GRP94, ERP44, ERP57 and ERP72.

Sepsis is the most common clinical condition in which acute lung injury and respiratory failure develops. Various studies have examined the effects of sepsis models on diaphragm contractility in spontaneously breathing animals $(4,26)$, however, few studies provide a comprehensive characterization of the physiological, structural and ultrastructural effects on the lungs and diaphragm. The present study employed a rat model of sepsis by injecting $8 \mathrm{mg} / \mathrm{kg}$ LPS intraperitoneally, a model which has been used in other studies $(7,27,28)$. Responses to LPS were also characterized, including the acute and recovery phases of the response, and the integration of such data may provide additional insights into the pathogenesis of the endotoxin response. In a previous study, which used the same model, $8 \mathrm{mg} / \mathrm{kg}$ LPS was administered, and decreased contractile force and FI of diaphragms was observed after $24 \mathrm{~h}$ (21). In the current study, this dose was administered to rats and diaphragm function was examined at $24,48 \mathrm{~h}$ and 7 days. It was observed that sepsis reduced $\mathrm{P}_{t}, \mathrm{FI}$ and contractile forces of the diaphragm, $\mathrm{P}_{0}$, to their lowest levels at $48 \mathrm{~h}$ following the initial LPS treatment. Suppression of diaphragm function was alleviated by day 7. Lung W/D was examined to evaluate the level of edema. Microscopic examination of lung tissues by $\mathrm{H} \& \mathrm{E}$ staining was employed to evaluate lung tissue injury, which was manifested by alveolar congestion, hemorrhage and inflammatory infiltration. Similar to diaphragm function, the degree of lung edema and injury peaked at $48 \mathrm{~h}$ and declined at day 7 . These results demonstrated that the level of lung injury was positively associated with diaphragm dysfunction. Regarding the association between lung injury and muscle dysfunction, it was assumed that lung injury led to decreased oxygen intake and the release of inflammatory mediators and free radical species including superoxide, nitric oxide and, the free radical-derived product, hydrogen peroxide (29-31). These factors may be involved in LPS- or infection-induced alterations in skeletal muscle function.

Sepsis is known to induce diaphragm muscle weakness, which in turn contributes to the development of respiratory failure. A number of studies have explored the mechanism of sepsis-induced diaphragm dysfunction and it has been reported that caspase-12 activation, RNA-dependent protein kinase activation and dysfunction of the calcium release mechanism are responsible for this effect $(32,33)$. In our previous study it was demonstrated that, in a septic rat model, expression of DHPRa1s and RyR1, which are essential for calcium release during excitation-contraction coupling in striated muscles, were reduced in the diaphragm (21). Accumulating evidence suggests that ER stress serves a role in the pathogenesis of muscle dysfunction (34-36). 
The involvement of ER stress has not been investigated in sepsis-induced diaphragm contractile weakness. The ultrastructural changes of ER in the diaphragm were investigated by EM. The results demonstrated swollen, distended ER and mitochondrial lesions of diaphragm muscle cells in septic rats, which indicated ER injury. This structural injury may be the result of changes at the molecular level $(37,38)$. In muscle cells, the sarcoplasmic reticulum, smooth ER found in myocytes, stores calcium ions and pumps them out into the cytoplasm following stimulation of the muscle fiber. After release from the ER, calcium ions interact with contractile proteins that utilize ATP to shorten the muscle fiber (39). It was assumed that, during the ER stress process, ER function is jeopardized and calcium ion flow is dysregulated, which leads to muscle dysfunction.

The ER is extremely sensitive to a variety of different stimuli, and signals are transduced from the ER to the cytoplasm and nucleus, eventually resulting in adaptation for survival or induction of apoptosis. In response, UPR genes are induced, increasing the capacity to fold proteins. The UPR is regulated by three ER transmembrane receptors, which mediate signal transduction: Inositol requiring ER-to-nucleus signal kinase 1 , activating transcription factor 6 and double-stranded RNA-activated kinase (protein kinase R)-like ER kinase (40). On accumulation of unfolded proteins, ER resident chaperones, including GRP78 and GRP94, are upregulated, which triggers the UPR (41). Subsequently, GRP78 and GRP94 bind to misfolded proteins to prevent forming aggregates and assists with correct refolding. The present study demonstrated that sepsis stimulated ER stress, as reflected by increased expression of GRP78 and GRP94, and by increased expression of CHOP, which are well-established markers of ER stress. The role of CHOP in ER-stressed cells is associated with its role in promoting protein synthesis and oxidative stress inside the ER. This study also observed that several other ER chaperones, including ERP44, ERP57 and ERP72 were upregulated in the diaphragm of septic rats (42-44). ERP57, ERP44 and ERP72 are suggested to be involved in the isomerization of disulfide bonds on certain glycoproteins during ER stress. During ER stress, these ER-associated proteins are activated and help to return proteins to their native conformation and to reconstitute cellular balance. Their expression reflects the level of ER stress. In addition, this study demonstrated that the level of ER stress-associated proteins peaked at $48 \mathrm{~h}$ and then declined at 7 days, which corresponded with the changes in diaphragm function, lung injury and ER damage. Several previous studies have indicated that ER stress is involved in muscle dysfunction. ER stress compromises cardiac contractile dysfunction in LPS-induced animal models and drugs that inhibit ER stress rescued ER stress-induced contractile dysfunction $(14,45,46)$. ER stress also causes muscle injury in rats with diabetic gastroparesis (47). To the best of our knowledge, the present study is the first to investigate protein and mRNA changes of ER stress markers in diaphragm muscles during sepsis and the results implicate ER stress in diaphragm weakness.

Extended ER stress may lead to caspase activation and cell apoptosis, which links sepsis-induced ER stress and diaphragm dysfunction. Caspase-12 activation is believed to have an important role in ER stress-induced muscle apoptosis (48). In a previous study, caspase-12 mediated ER-specific apoptosis and mice with caspase-12 deficiency became resistant to apoptosis induced by ER stress (49). Upregulation of cleaved caspase-12 was also observed in myocardial apoptosis induced by ER stress $(50,51)$. The current study demonstrated that cleaved caspase-12 expression is increased in the diaphragm of septic rats, suggesting that ER stress-induced apoptosis occurs in diaphragm muscle cells, which may eventually lead to muscle weakness.

In conclusion, the present study demonstrated that the weakened diaphragm contraction observed in septic rats is associated with lung tissue injury, ER damage and elevated mRNA and protein expression of ER stress markers. These results further support the hypothesis that ER stress was enhanced in the diaphragm and that diaphragm weakness was, at least partially, induced by ER stress in septic rats. The present study provides a novel insight into the mechanisms required for the development of sepsis-induced diaphragm dysfunction. Further studies are required to investigate signal transduction in ER stress, which may improve the characterization of the development of respiratory failure.

\section{Acknowledgements}

The present study was supported by the National Natural Science Foundation of China (grant nos. 81170068, 31071004 and 81100108 ). This abstract has been previously published as part of the proceedings of the American Thoracic Society 2016 in San Francisco (CA, USA) on May 13-18, 2016.

\section{References}

1. Sprung CL, Annane D, Keh D, Moreno R, Singer M, Freivogel K, Weiss YG, Benbenishty J, Kalenka A, Forst H, et al: Hydrocortisone therapy for patients with septic shock. N Engl J Med 358: 111-124, 2008.

2. Wilson TA, Legrand A, Gevenois PA and De Troyer A: Respiratory effects of the external and internal intercostal muscles in humans. J Physiol 530: 319-330, 2001.

3. Supinski G, Nethery D, Stofan D and DiMarco A: Comparison of the effects of endotoxin on limb, respiratory, and cardiac muscles. J Appl Physiol (1985) 81: 1370-1378, 1996.

4. Shindoh C, Murakami Y, Shishido R, Sasaki K, Nishio T and Miura M: Tulobuterol patch maintains diaphragm muscle contractility for over twenty-four $\mathrm{h}$ in a mouse model of sepsis. Tohoku J Exp Med 218: 271-278, 2009.

5. Lanone S, Taillé C, Boczkowski J and Aubier M: Diaphragmatic fatigue during sepsis and septic shock. Intensive Care Med 31: 1611-1617, 2005.

6. Supinski GS and Callahan LA: Calpain activation contributes to endotoxin-induced diaphragmatic dysfunction. Am J Respir Cell Mol Biol 42: 80-87, 2010.

7. Callahan LA and Supinski GS: Sepsis induces diaphragm electron transport chain dysfunction and protein depletion. Am J Respir Crit Care Med 172: 861-868, 2005.

8. Ron D and Walter P: Signal integration in the endoplasmic reticulum unfolded protein response. Nat Rev Mol Cell Biol 8: 519-529, 2007.

9. Deniaud A, Sharaf el dein O, Maillier E, Poncet D, Kroemer G, Lemaire $\mathrm{C}$ and Brenner $\mathrm{C}$ : Endoplasmic reticulum stress induces calcium-dependent permeability transition, mitochondrial outer membrane permeabilization and apoptosis. Oncogene 27: 285-299, 2008.

10. Zhao L and Ackerman SL: Endoplasmic reticulum stress in health and disease. Curr Opin Cell Biol 18: 444-452, 2006.

11. Li SY, Gilbert SA, Li Q and Ren J: Aldehyde dehydrogenase-2 (ALDH2) ameliorates chronic alcohol ingestion-induced myocardial insulin resistance and endoplasmic reticulum stress. J Mol Cell Cardiol 47: 247-255, 2009. 
12. Miki T, Miura T, Hotta H, Tanno M, Yano T, Sato T, Terashima Y, Takada A, Ishikawa S and Shimamoto K: Endoplasmic reticulum stress in diabetic hearts abolishes erythropoietin-induced myocardial protection by impairment of phospho-glycogen synthase kinase-3beta-mediated suppression of mitochondrial permeability transition. Diabetes 58: 2863-2872, 2009.

13. Minamino T, Komuro I and Kitakaze M: Endoplasmic reticulum stress as a therapeutic target in cardiovascular disease. Circ Res 107: 1071-1082, 2010.

14. Zhang Y, Xia Z, La Cour KH and Ren J: Activation of Akt rescues endoplasmic reticulum stress-impaired murine cardiac contractile function via glycogen synthase kinase- $3 \beta$-mediated suppression of mitochondrial permeation pore opening. Antioxid Redox Signal 15: 2407-2424, 2011.

15. Sassoon CS, Caiozzo VJ, Manka A and Sieck GC: Altered diaphragm contractile properties with controlled mechanical ventilation. J Appl Physiol (1985) 92: 2585-2595, 2002.

16. Sassoon CS, Zhu E, Fang L, Ramar K, Jiao GY and Caiozzo VJ: Interactive effects of corticosteroid and mechanical ventilation on diaphragm muscle function. Muscle Nerve 43: 103-111, 2011.

17. Wolthuis EK, Vlaar AP, Hofstra JJ, Roelofs JJ, de Waard V, Juffermans NP and Schultz MJ: Plasminogen activator inhibitor-type I gene deficient mice show reduced influx of neutrophils in ventilator-induced lung injury. Crit Care Res Pract 2011: 217896, 2011

18. Rojas M, Woods CR, Mora AL, Xu J and Brigham KL: Endotoxin-induced lung injury in mice: Structural, functional and biochemical responses. Am J Physiol Lung Cell Mol Physiol 288: L333-L341, 2005.

19. Gupta N, Su X, Popov B, Lee JW, Serikov V and Matthay MA: Intrapulmonary delivery of bone marrow-derived mesenchymal stem cells improves survival and attenuates endotoxin-induced acute lung injury in mice. J Immunol 179: 1855-1863, 2007.

20. Li J, Li D, Liu X, Tang S and Wei F: Human umbilical cord mesenchymal stem cells reduce systemic inflammation and attenuate LPS-induced acute lung injury in rats. J Inflamm (Lond) 9: 33, 2012.

21. Jiao GY, Hao LY, Gao CE, Chen L, Sun XF, Yang HL, Li Y and Dai YN: Reduced DHPR $1 \mathrm{~S}$ and RyR1 expression levels are associated with diaphragm contractile dysfunction during sepsis. Muscle Nerve 48: 745-751, 2013.

22. Burke RE, Levine DN, Tsairis P and Zajac FE III: Physiological types and histochemical profiles in motor units of the cat gastrocnemius. J Physiol 234: 723-748, 1973.

23. Livak KJ and Schmittgen TD: Analysis of relative gene expression data using real-time quantitative PCR and the 2(-Delta Delta C(T)) Method. Methods 25: 402-408, 2001

24. Khan MM, Yang WL and Wang P: Endoplasmic reticulum stress in sepsis. Shock 44: 294-304, 2015.

25. Ma T, Han L and Hu WQ: Study of the role of endoplasmic reticulum stress mediated apoptosis signal pathway in sepsis-induced splenic lymphocyte apoptosis. Zhongguo Wei Zhong Bing Ji Jiu Yi Xue 21: 48-50, 2009 (In Chinese).

26. Narimatsu E, Nakayama Y, Sumita S, Iwasaki H, Fujimura N Satoh K and Namiki A: Sepsis attenuates the intensity of the neuromuscular blocking effect of d-tubocurarine and the antagonistic actions of neostigmine and edrophonium accompanying depression of muscle contractility of the diaphragm. Acta Anaesthesiol Scand 43: 196-201, 1999.

27. Supinski GS, Wang W and Callahan LA: Caspase and calpain activation both contribute to sepsis-induced diaphragmatic weakness. J Appl Physiol (1985) 107: 1389-1396, 2009.

28. Doi K, Leelahavanichkul A, Yuen PS and Star RA: Animal models of sepsis and sepsis-induced kidney injury. J Clin Invest 119: 2868-2878, 2009

29. Peng H, Chen Q and Tan Y: Frequent ejaculation associated free radical and lactic acid accumulation cause noninfectious inflammation and muscle dysfunction: A potential mechanism for symptoms in Chronic Prostatitis/Chronic Pelvic Pain Syndrome. Med Hypotheses 73: 372-373, 2009.

30. Supinski GS and Callahan LA: Free radical-mediated skeletal muscle dysfunction in inflammatory conditions. J Appl Physiol (1985) 102: 2056-2063,2007.

31. Supinski G: Free radical induced respiratory muscle dysfunction. Mol Cell Biochem 179: 99-110, 1998.

32. Liu SH, Lai JL, Yang RS and Lin-Shiau SY: Nitric oxide is not involved in the endotoxemia-induced alterations in $\mathrm{Ca}^{2+}$ and ryanodine responses in mouse diaphragms. Naunyn Schmiedebergs Arch Pharmacol 366: 327-334, 2002.
33. Supinski GS and Callahan LA: Double-stranded RNA-dependent protein kinase activation modulates endotoxin-induced diaphragm weakness. J Appl Physiol (1985) 110: 199-205, 2011.

34. Bohnert KR, Gallot YS, Sato S, Xiong G, Hindi SM and Kumar A: Inhibition of ER stress and unfolding protein response pathways causes skeletal muscle wasting during cancer cachexia. FASEB J 30: 3053-3068, 2016.

35. Deldicque L, Bertrand L, Patton A, Francaux M and Baar K: ER stress induces anabolic resistance in muscle cells through PKB-induced blockade of mTORC1. PLoS One 6: e20993, 2011.

36. Chalil S, Pierre N, Bakker AD, Manders RJ, Pletsers A, Francaux M, Klein-Nulend J, Jaspers RT and Deldicque L: Aging related ER stress is not responsible for anabolic resistance in mouse skeletal muscle. Biochem Biophys Res Commun 468: 702-707, 2015.

37. Hrincius ER, Liedmann S, Finkelstein D, Vogel P, Gansebom S, Samarasinghe AE, You D, Cormier SA and McCullers JA: Acute lung injury results from innate sensing of viruses by an ER stress pathway. Cell Rep 11: 1591-1603, 2015.

38. Inagi R, Nangaku M, Onogi H, Ueyama H, Kitao Y, Nakazato K, Ogawa S, Kurokawa K, Couser WG and Miyata T: Involvement of endoplasmic reticulum (ER) stress in podocyte injury induced by excessive protein accumulation. Kidney Int 68: 2639-2650, 2005.

39. Yao $X$, Li Y, Cheng $X$ and Li H: ER stress contributes to alpha-naphthyl isothiocyanate-induced liver injury with cholestasis in mice. Pathol Res Pract 212: 560-567, 2016.

40. Mori K: Tripartite management of unfolded proteins in the endoplasmic reticulum. Cell 101: 451-454, 2000.

41. Travers KJ, Patil CK, Wodicka L, Lockhart DJ, Weissman JS and Walter P: Functional and genomic analyses reveal an essential coordination between the unfolded protein response and ER-associated degradation. Cell 101: 249-258, 2000.

42. Vattemi G, Engel WK, McFerrin J and Askanas V: Endoplasmic reticulum stress and unfolded protein response in inclusion body myositis muscle. Am J Pathol 164: 1-7, 2004.

43. Dihazi H, Dihazi GH, Bibi A, Eltoweissy M, Mueller CA Asif AR, Rubel D, Vasko R and Mueller GA: Secretion of ERP57 is important for extracellular matrix accumulation and progression of renal fibrosis, and is an early sign of disease onset. J Cell Sci 126: 3649-3663, 2013.

44. Simmen T, Lynes EM, Gesson K and Thomas G: Oxidative protein folding in the endoplasmic reticulum: Tight links to the mitochondria-associated membrane (MAM). Biochim Biophys Acta 1798: 1465-1473, 2010

45. Ceylan-Isik AF, Zhao P, Zhang B, Xiao X, Su G and Ren J: Cardiac overexpression of metallothionein rescues cardiac contractile dysfunction and endoplasmic reticulum stress but not autophagy in sepsis. J Mol Cell Cardiol 48: 367-378, 2010.

46. Zhang B, Zhang Y, La Cour KH, Richmond KL, Wang XM and Ren J: Mitochondrial aldehyde dehydrogenase obliterates endoplasmic reticulum stress-induced cardiac contractile dysfunction via correction of autophagy. Biochim Biophys Acta 1832: 574-584, 2013

47. Chen X, Fu XS, Li CP and Zhao HX: ER stress and ER stress-induced apoptosis are activated in gastric SMCs in diabetic rats. World J Gastroenterol 20: 8260-8267, 2014.

48. Di Sano F, Ferraro E, Tufi R, Achsel T, Piacentini M and Cecconi F: Endoplasmic reticulum stress induces apoptosis by an apoptosome-dependent but caspase 12-independent mechanism. J Biol Chem 281: 2693-2700, 2006.

49. Nakagawa T, Zhu H, Morishima N, Li E, Xu J, Yankner BA and Yuan J: Caspase-12 mediates endoplasmic-reticulum-specific apoptosis and cytotoxicity by amyloid-beta. Nature 403: 98-103, 2000.

50. Ding W, Zhang X, Huang H, Ding N, Zhang S, Hutchinson SZ and Zhang X: Adiponectin protects rat myocardium against chronic intermittent hypoxia-induced injury via inhibition of endoplasmic reticulum stress. PLoS One 9: e94545, 2014

51. Yao W, Gu H, Zhu J, Barding G, Cheng H, Bao B, Zhang L, Ding $\mathrm{A}$ and $\mathrm{Li} \mathrm{W}$ : Integrated plasma and urine metabolomics coupled with HPLC/QTOF-MS and chemometric analysis on potential biomarkers in liver injury and hepatoprotective effects of Er-Zhi-Wan. Anal Bioanal Chem 406: 7367-7378, 2014 